\section{Ensino médio público no passado e no presente: visões de docentes de distintas gerações do Distrito Federal}

\author{
Wivian Weller ${ }^{\mathrm{I}, \mathrm{II}}$ \\ Cilene Vilarins Cardoso da Silva ${ }^{\mathrm{III}, \mathrm{IV}}$
}

https://doi.org/10.24109/2176-6681.rbep.102.i260.4451

\section{Resumo}

No ano em que Brasília comemora seus 60 anos e em que novas mudanças estão em vigor nas escolas de ensino médio em função da implementação da Lei $n^{\circ}$ 13.415/2017, faz-se necessário estabelecer um debate sobre os novos rumos do ensino médio no Distrito Federal e no País, sem esquecer o que já foi conquistado e o que a história pode nos ensinar. Nesse sentido, torna-se importante ouvir docentes de distintas gerações que atuaram ou ainda estão atuando em escolas de ensino médio, considerando que suas experiências na docência e na implementação de reformas desde a década de 1970 podem contribuir para o entendimento do ensino médio tanto no passado como no presente. Com base em grupos de discussão, o artigo analisa as orientações coletivas de distintas gerações de professores, levando em conta suas experiências passadas enquanto estudantes dessa etapa e suas visões a partir do momento em que se tornaram docentes. A particularidade deste estudo consiste em considerar as vozes de docentes que pertencem a gerações diversas, mas que coexistem no mesmo espaço e no mesmo tempo, o que gera por vezes conflitos e tensões e, em outros momentos, diálogos, compartilhamentos e aprendizados.

Palavras-chave: avaliação da educação; Distrito Federal; formação de professores; sistema de ensino estadual. 


\section{Abstract \\ Public high school in the past and in the present: visions of multiple generation teachers of Federal District}

In the year Brasilia celebrates its 60th anniversary and new changes are in effect in high schools due to the implementation of the legal document Lei $n^{\circ} 13.415 / 2017$, it must be established a debate on the new directions of high school in the Federal District and in the country, without forgetting past achievements and what history can teach us. In this sense, it is important to listen to teachers from different generations who worked or are still working in high schools, considering that their experiences, teaching and implementing reforms since the 1970s, can help to understand high school both in the past and present. Based on group discussions, the article analyzes the collective guidelines of different generations of teachers, considering their own past experiences as students and their views from the moment they became teachers. The particularity of this study lies in the fact it considers the opinions of teachers coming from different generations, but who coexist at the same time and space; which may lead to conflicts and tensions, as well as to dialogues, sharing and learning.

Keywords: Distrito Federal; educational assessment; municipal school system; teacher training.

\section{Resumen \\ Educación secundaria pública en el pasado y en el presente: visiones de docentes de diferentes generaciones del Distrito Federal}

En el año en que Brasilia celebra su $60^{\circ}$ aniversario y en el que están vigentes nuevos cambios en las escuelas secundarias debido a la implementación de la Ley $n .^{\circ}$ 13.415/2017, es necesario establecer un debate sobre las nuevas direcciones de la escuela secundaria en el Distrito Federal y en el país, sin olvidar lo que ya se conquistó y lo que la historia nos puede enseñar. En este sentido, es importante escuchar a los docentes de diferentes generaciones que trabajaron o siguen trabajando en las escuelas secundarias, teniendo en cuenta que sus experiencias en la enseñanza y en la implementación de reformas desde la década de 1970 pueden contribuir a la comprensión de la escuela secundaria, tanto en el pasado como en el presente. Basado en grupos de discusión, el artículo analiza las orientaciones colectivas de diferentes generaciones de docentes, considerando sus experiencias pasadas como estudiantes en esta etapa y sus puntos de vista desde el momento en que se convirtieron en docentes. La particularidad de este estudio es en el sentido de considerar las voces de los docentes, que pertenecen a diferentes generaciones, pero que coexisten en el mismo 
espacio y al mismo tiempo, a veces generando conflictos, tensiones $y$, en otras ocasiones, diálogos, compartiendo y aprendiendo.

Palabras clave: evaluación de la educación; Distrito Federal; formación de profesores; sistema de educación estatal.

\section{Introdução: breves considerações sobre o sistema educacional e as escolas de ensino médio no Distrito Federal}

No ano em que Brasília comemora seus 60 anos, retomamos, inicialmente, a proposta de Anísio Teixeira e o plano de educação inovador que ele havia preconizado para a capital do País, com o intuito de adequar o sistema educacional ao estado democrático moderno. De acordo com o educador, os espaços físicos deveriam contribuir para que as escolas pudessem desenvolver projetos inovadores, voltados para a expansão da sociedade moderna e de um sistema de ensino que colaborasse com o seu desenvolvimento. Dessa forma, propôs a construção de centros de educação, com a seguinte organização: a) Centros de Educação Elementar, integrados por jardins da infância, escolas classe e escolas-parque; b) Centros de Educação Média, destinados à Escola Secundária Compreensiva e ao Parque de Educação Média; c) Universidade de Brasília, composta de institutos, faculdades e demais dependências destinadas à administração, à biblioteca e aos campos de recreação e desportos (Teixeira, 1961).

Os Centros de Educação Média deveriam propiciar aos jovens o desenvolvimento de suas aptidões e habilidades mediante a interação com seus pares e a orientação de grupos de professores. Mesmo matriculados em cursos de nível médio distintos, a proposta era permitir a socialização entre todos os jovens que frequentavam os centros, por exemplo, em atividades culturais e esportivas e por meio da utilização de espaços comuns, como a biblioteca e o refeitório. Assim, esses centros preparariam as futuras gerações tanto para o mercado de trabalho quanto para a continuidade dos estudos. Preconizava-se para os Centros de Educação Média uma proposta de formação ampliada a ser ofertada em tempo integral (Vasconcelos, 2018). Todas as unidades deveriam oferecer três modalidades de estudos em período integral: a) curso geral prático, a ser ministrado para todos os estudantes ou para a grande maioria, voltado para a formação de uma cultura geral, com ênfase em Língua Portuguesa, Literatura Brasileira, Matemática e Ciências Físicas e Sociais Aplicadas; b) cursos com ênfase em línguas estrangeiras e estudos teóricos, como aprofundamento do curso geral, para aqueles que se mostrassem interessados ou capazes de estudos dessa natureza; e c) cursos técnicos, para os inclinados à especialização tecnológica (Pereira; Rocha, 2011).

No entanto, com o desenvolvimento da nova capital federal e o aumento populacional, a ampliação do número de escolas de nível médio era urgente não só na região central, como também nas regiões distantes, denominadas 
à época de cidades satélites ${ }^{1}$, de forma que o Plano de Construções Escolares de Brasília proposto por Anísio Teixeira não chegou a ser totalmente implementado. A fim de atender minimamente a demanda, foram criadas algumas escolas de ensino médio entre 1957 e 1964 no Plano Piloto (atual região administrativa de Brasília), em Taguatinga, em Planaltina e no Núcleo Bandeirante. Os processos migratórios nos anos seguintes forçaram a expansão do sistema de ensino, e um número significativo de escolas públicas foi inaugurado a partir dos anos 1970. Essas escolas passaram a oferecer a formação em nível médio de acordo com a Lei no 5.692/71, que implementou o ensino de $2^{\circ}$ grau de três anos com ênfase na diversificação de percursos profissionalizantes. A oferta nas regiões administrativas mais distantes da região central era realizada sobretudo no período noturno, uma vez que algumas dessas escolas atendiam turmas do $1^{\circ}$ grau nos turnos diurno e vespertino.

Com a abertura política a partir de 1985 e os avanços registrados a partir da promulgação da Constituição de 1988 e da Lei de Diretrizes e Bases da Educação Nacional (LDB), Lei no 9.394/96, o Distrito Federal, assim como os estados da Federação, acompanhou as mudanças curriculares propostas nas Diretrizes Curriculares Nacionais para o Ensino Médio (DCNEM) e ampliou a oferta do ensino médio, para que todos os estudantes ao final do ensino fundamental, que assim desejassem, pudessem ingressar na última etapa da educação básica. Em 2009, com a aprovação da Emenda Constitucional $n^{\circ} 59$, a frequência às instituições de ensino foi definida dos 4 aos 17 anos. Nesse sentido, o ensino médio tornou-se obrigatório para todos os jovens que concluíram o ensino fundamental com menos de 17 anos.

Ferreira (2019), utilizando dados do Instituto Brasileiro de Geografia e Estatística (IBGE)/2013 e do Censo Escolar/2014, destaca que o ensino médio público no Distrito Federal conta com 87 escolas, com ofertas em três formas de organização escolar: a regular anual clássica, a semestral e o ensino médio integrado à educação profissional, nos turnos diurno e noturno. Com relação à localização geográfica, 78 unidades estão na zona urbana e 9 na zona rural. De acordo com dados do último Censo Escolar, as matrículas no ensino médio permaneceram relativamente estáveis nos últimos cinco anos, atingindo 79.741 estudantes em 2018 (Brasil. Inep, 2019).

Para Krawczyk (2011, p. 745), "a inclusão do ensino médio no âmbito da educação básica e o seu caráter progressivamente obrigatório demonstram o reconhecimento da importância política e social que ele possui". Atualmente, a discussão alusiva à oferta requer não só a garantia das vagas necessárias, mas também um debate mais amplo em torno de projetos como a escola em tempo integral e a semestralidade implementada no Distrito Federal (Simões; Dartora; Deus, 2017). Novas mudanças estão em vigor em função da Lei no 13.415/2017, que determina outra organização para o ensino médio. Faz-se necessário estabelecer um debate sobre os novos rumos dessa etapa no Distrito Federal e no País, sem esquecer o que já foi conquistado e o que a história pode nos ensinar. Nesse sentido, torna-se importante ouvir os professores de distintas gerações que atuaram ou ainda
Essas regiões passaram a ser habitadas sobretudo pelas famílias dos operários da construção civil, também denominados de "candangos", uma marca linguística que reforça o discurso de exclusão desses novos habitantes (Tatagiba; Silva, 2013). 
estão atuando em escolas de ensino médio, considerando tempos e espaços distintos. Suas experiências na docência e na implementação de reformas desde a década de 1970 podem contribuir para o entendimento dos sentidos e significados do ensino médio ao longo da história e oferecer uma melhor compreensão do ensino médio atual. Com base em grupos de discussão, o presente artigo analisa as orientações coletivas de distintas gerações de professores, considerando suas experiências passadas enquanto estudantes dessa etapa e suas visões a partir do momento em que se tornaram docentes.

\section{Pesquisas com docentes de distintas gerações em escolas públicas no Distrito Federal}

Pesquisas com e sobre docentes que atuam no ensino médio e, especialmente, com docentes de distintas gerações ainda são escassas, sobretudo no Distrito Federal. Além da investigação que será apresentada neste artigo, encontramos apenas um trabalho abordando a temática. $\mathrm{Na}$ tese "Contando uma história: o ensino público de línguas estrangeiras a partir das interpretações de jovens e de docentes do Distrito Federal", Damasco (2014) buscou compreender, por um lado, os sentidos e significados da língua estrangeira para o jovem da rede pública do Distrito Federal e, por outro, as motivações de docentes iniciantes e docentes pioneiros de línguas estrangeiras que atuaram nos anos 1970-1980 em centros de línguas públicos da Secretaria de Estado de Educação do Distrito Federal (SEEDF). A pesquisadora realizou grupos de discussão com jovens que estudavam línguas estrangeiras, grupos de discussão com docentes em início da carreira e entrevistas narrativas com docentes pioneiros, que atuaram fortemente na política de implementação do ensino de línguas nas escolas públicas da nova capital. Segundo a autora, foram evidenciadas diferenças significativas entre os docentes. O maior destaque se dá na concepção de docência: os professores mais antigos veem a profissão como uma escolha para toda a vida, já os iniciantes acreditam que ser professor de línguas é apenas um passo que os auxiliará a ingressar em outra carreira profissional.

Na pesquisa que será apresentada neste artigo, optou-se por realizar um estudo diacrônico em uma instituição de ensino médio localizada na região administrativa do Gama, com o objetivo de reunir informações sobre a escola de nível médio mais antiga dessa localidade e conhecer docentes que nela atuam ou atuaram. Dessa forma, buscou-se acessar a memória de professores mais antigos (alguns já aposentados), bem como as visões de docentes mais jovens que atuam no ensino médio na respectiva escola. Por meio da realização e análise de grupos de discussão (Bohnsack, 2014b), foi possível contrastar as orientações coletivas dos professores mais antigos - sobre como era o ensino médio quando eles eram estudantes e quando se tornaram professores dessa etapa - com as orientações coletivas da nova geração de docentes. Também foi possível conhecer narrativas acerca da escola e da comunidade com base na visão de professores de distintas gerações, considerando o contexto temporal e geracional, suas relações 
com os estudantes e com outros atores tanto na escola como na região administrativa do Gama.

\section{Sobre a pesquisa de campo e análise dos grupos de discussão}

Acompanhando Damasco (2014), os critérios para a realização do trabalho de campo primaram pela abordagem qualitativa reconstrutiva, considerando os interesses teóricos, os sujeitos e o contexto em que ocorreu a pesquisa. Nesse sentido, os critérios para a seleção dos participantes não foram definidos aleatoriamente, mas por meio da construção de um corpus com base no conhecimento e na experiência dos sujeitos. Para orientar os grupos de discussão em nossa investigação, foi construído um roteiro designado de tópico-guia, que auxiliou a condução do debate dos temas propostos. Ao final de cada grupo, foi solicitado que os professores apresentassem temas que não haviam sido observados e que eles consideravam importantes. Ao todo, 20 professores que trabalham ou trabalharam em regime de dedicação exclusiva na SEEDF participaram da pesquisa, totalizando quatro grupos de discussão, realizados no ano de 2016. Estes foram organizados com base nos seguintes critérios: professores que atuam e/ou atuaram por um período entre 25 e 35 anos na educação básica na SEEDF; e professores iniciantes, com menos de 10 anos de atuação na educação básica na SEEDF. Entre os 12 professores mais antigos, 7 iniciaram sua carreira no magistério nas séries iniciais, com a formação em nível médio, passando a integrar o grupo de docentes do ensino médio somente após a conclusão do curso superior, e 5 iniciaram sua carreira já como professores do ensino médio. Dois daqueles mais antigos já estão aposentados. Os oito professores iniciantes ingressaram na carreira do magistério já atuando no ensino médio, após a conclusão dos estudos de graduação. Importante destacar que a distinção entre gerações não pode levar em conta apenas o coorte etário, mas deve considerar, sobretudo, a conjuntura histórica, social e política que caracteriza um grupo como pertencente a uma determinada geração (Mannheim, 1993).

Para a análise em profundidade, realizada por meio do Método Documentário desenvolvido por Ralf Bohnsack com base na Sociologia do Conhecimento de Karl Mannheim (Bohnsack, 2014a, 2014b; Bohnsack e Weller, 2013), selecionamos um grupo formado por professores antigos, grupo Outrora, e outro composto por professores iniciantes, grupo Presente. O grupo Outrora contou com a participação de cinco professores (três mulheres e dois homens) entre 47 e 67 anos de idade e de 25 a 35 anos de atuação na SEEDF, que lecionam ou lecionaram as seguintes disciplinas: História (dois professores), Língua Portuguesa, Matemática e Psicologia. O grupo Presente foi constituído por três professores (duas mulheres e um homem) entre 28 e 31 anos de idade e de 3 a 7 anos de atuação na SEEDF, que lecionam as seguintes disciplinas: Física, História e Língua Portuguesa. Ambos os grupos foram convidados a narrar suas experiências enquanto 
estudantes e como professores do ensino médio, suas percepções sobre a juventude quando eles eram jovens e na atualidade e suas experiências na docência, em especial na escola em que aconteceu a pesquisa. Nesse sentido, buscamos articular dois conceitos no processo de análise dos grupos de discussão: memória e orientações coletivas.

De acordo com Bosi (1994, p. 9), "a memória é um cabedal infinito do qual só registramos um fragmento". Geralmente, esses fragmentos que emergem em um grupo de discussão são os acontecimentos mais marcantes e compartilhados pelo coletivo ou aqueles que, de algum modo, influenciaram certas atitudes e formas de pensar. A autora argumenta que:

[...] a memória permite a relação do corpo presente com o passado e, ao mesmo tempo, interfere no processo 'atual' das representações. Pela memória, o passado não só vem à tona das águas presentes, misturandose com as percepções imediatas, como também empurra, 'desloca' estas últimas, ocupando o espaço todo da consciência. (Bosi, 1987, p. 9).

Fundamentando-se nessa concepção, as narrativas dos professores foram analisadas mediante a memória ressignificada, o que permitiu confrontar a memória de suas experiências passadas com suas visões sobre os jovens e o ensino médio na atualidade.

No âmbito do Método Documentário, passou-se a adotar o conceito de orientações coletivas na reconstrução de padrões de significação coletiva, que emanam nos grupos de discussão. Nesse sentido, a reconstrução de orientações coletivas que estão vinculadas a um espaço social de experiências conjuntivas, como definido por Mannheim (1982), representa um elemento central do método. No contexto de um grupo de discussão, por exemplo, com professores de uma escola, essas orientações coletivas podem ser identificadas na intensificação recíproca do debate:

[...] que pode se expressar não só na densidade crescente da interação, mas também em uma condensação crescente do significado do conteúdo [que ocorre de forma ainda mais intensa] quando o discurso é sustentado por vivências comuns, por uma socialização conjunta, por um contexto social comum. (Bohnsack, 2014, p. 42).

No caso dos professores que participaram dos grupos de discussão, o contexto social comum está representado pela escola em que atuam e pelas vivências comuns na condição de estudantes do ensino médio em uma determinada época, como discutiremos a seguir.

\section{O ensino médio no passado e no presente: análise dos grupos de discussão}

Considerando as discussões recentes em torno do ensino médio e a necessidade de delimitarmos o foco do artigo, apresentaremos somente as narrativas dos docentes sobre o ensino médio no passado, quando foram estudantes dessa etapa, seguida da análise acerca do ensino médio na atualidade, a partir do olhar enquanto docentes. 
Grupo Outrora: "a escola tinha um sentido útil, prático"

O grupo de discussão teve início com uma pergunta que buscou incentivar a narrativa dos professores que, voltando no tempo, trouxeram para o presente suas lembranças sobre como percebiam o ensino médio quando estudantes. É possível que os resultados dessas memórias estejam afetados com as impressões atuais dos participantes, visto que o processo histórico altera o modo de perceber do indivíduo (passagem inicial: ensino médio no passado²).

Y: Eu gostaria que vocês falassem como foi a experiência de vocês durante o segundo grau, o que vocês acham, onde vocês fizeram o segundo grau, como foi a experiência de vocês no ensino médio enquanto alunos, como foi a formação de vocês

Ef: Eu estudei no Colégio XX, um colégio particular na cidade de Januária Minas Gerais (.) eu nunca estudei em escola pública (.) meu pai era fazendeiro e tinha aquelas manias de que fazendeiros não colocavam filhos em escola pública, mas o que eu esperava do ensino médio naquela época que era outro nome (1) acho que era ginásio então, a gente fazia o ginásio, eu queria ser professora (1) eu queria ser professora, meu sonho era ser professora (.) e naquela época, era importante ser professora, era importante ser bancário (.) toda menina queria casar com alguém que trabalhasse no Banco do Brasil e todo rapaz queria namorar com uma moça que fizesse curso magistério, né inclusive tinha até aquela música (.) minha normalista linda? a normalista que a coisa mais linda que tinha (.) de uniforme, tudo bonitinho (.)

Cf: Na nossa vida acadêmica (1) apesar de não termos as matérias para vestibular, na minha turma, 34 alunos queriam fazer vestibular (.)

Bm: Fiz o ensino médio em Pernambuco (1) Técnico em Contabilidade, no Colégio XX, era na época em que ainda existia o profissionalizante (.)

\section{Cf: O meu era Administração (.)}

Am:Eu estudei aqui também, fiz ensino médio e, na época, não sei bem por que (.) a escola era profissionalizante (1) eles abriram uma turma que seria hoje o científico (.)

Cf: L Isso mesmo?

Am:A nossa turma era chamada (3) a gente até brincava com um canto de guerra que era assim (.) é 7044? é única? é única? porque só tinha ela (.) era Normal, Administração, Contabilidade

Cf:L Verdade uma coisa interessante também era que os professores não tinham muita ausência de professores, eles não faltavam tanto, não havia por que (.) não tinha muito desgaste, tanto e eu associo isso às licenças prêmio (.)

Ef: Agora, nessa época eu dei aula para o magistério, foi maravilhosa também (.) não tinha tanta mudança, não tinha tanta mudança, o ensino médio do magistério era muito bom, era um curso profissionalizante, você saía professora de lá (.) o segundo grau de contabilidade, de administração, o científico, eletrônica, era profissionalizante que depois com tanta reforma, com tanta reforma, que eu não sei pra quê, acabou (.)

Df: A minha experiência como estudante no ensino médio, antigo segundo grau foi extraordinária primeiro porque considero que foi a fase que eu comecei a me constituir como sujeito sabe (2) a identidade nossa toma todo contorno aqui (.) nessa fase porque temos em média 14, 15 anos o meu segundo grau fiz na Escola Normal de XXXX. fiz o curso
2 Neste artigo, optou-se por apresentar as transcrições dos grupos de discussão utilizando os códigos criados pelos pesquisadores que compunham o grupo coordenado por Ralf Bohnsack (Weller, 2006). Nesse sentido, os sinais de pontuação não são utilizados de acordo com as normas ortográficas da Língua Portuguesa. As palavras em itálico referem-se à pronúncia de forma enfática ou em tom elevado de voz. 
de Magistério (.) eu era subversiva, contestadora e revolucionária e o curso Normal era quadradinho, cheio de regras, além do que funcionava dentro de uma escola constituída com todas as bases militares, elitista e etc. (.) então era um embate constante entre o que eu era e o que o curso queria fazer comigo (.) como não me rendia tive um segundo grau muito marcado pelas (3) imposições do curso (.) tomei a decisão de fazer um curso técnico profissionalizante porque naquele tempo filho de pobre tinha unicamente essa opção (.) o curso que escolhi me levaria direto para um ótimo emprego? professora

Entre os participantes do grupo Outrora, dois haviam cursado o antigo $2^{\circ}$ grau em outros estados (Ef e Bm) e três estudaram em escolas recém-criadas no Distrito Federal (Cf, Am e Df). Am foi o único que cursou essa etapa na modalidade "científico" e relata haver se tratado da única turma em sua escola, o que conferia aos alunos um título de exclusividade, como lembrado no "canto de guerra" proferido por eles naquela época: "E 7044! É única! É única!". Os outros participantes seguiram os cursos profissionalizantes comumente oferecidos nas escolas públicas e com grandes possibilidades de emprego após a conclusão: Administração, Contabilidade e Magistério. Entre as duas estudantes que cursaram o Magistério, destaca-se a escolha por questões de prestígio e reconhecimento, mas também pela garantia de trabalho após a conclusão do curso.

A importância do antigo $2^{\circ}$ grau parece estar associada a um fim prático e imediato, ou seja, um diploma valorizado no mercado e nos relacionamentos ("todo rapaz queria namorar com uma moça que fizesse curso magistério"), mas, sobretudo, um diploma ligado a uma posição diferenciada na sociedade, o qual permitia o exercício de funções laborais que não haviam sido alcançadas por seus pais. Assim, a possibilidade de emprego imediato e a melhoria da condição socioeconômica de suas famílias fizeram com que esses professores atribuíssem um sentido altamente positivo ao antigo $2^{\circ}$ grau, a ponto de questionarem o término deste ("que depois com tanta reforma, com tanta reforma, que eu não sei pra quê, acabou").

Ao serem questionados sobre o ensino médio na atualidade, as comparações com o $2^{\circ}$ grau profissionalizante instituído durante a ditadura militar foram constantes. A discussão exposta a seguir decorre de uma pergunta anterior da pesquisadora $Y$, na qual os participantes debatiam a relação deles com os estudantes na escola em que estavam atuando (ensino médio no presente).

Y: E pra vocês (.) hoje o ensino médio hoje é só uma fase

Am: Vai editar né? quando eu comparo assim, o ensino médio que eu estudei e o ensino médio que eu trabalho, eu vivo uma indefinição, tenho até receio de cair no saudosismo, mas eu consigo entender (.) como eu já falei antes que para a nossa época. a escola tinha um sentido útil (.) prático (.) era colocar você no mercado de trabalho, garantir que você se livrasse por exemplo (.) de empregos braçais (.) serviços braçais, ser diarista como a mãe, ser atendente, ser um porteiro (.) então a conclusão do ensino médio, do antigo segundo grau era uma garantia quase certa de (2) de uma ascensãozinha social você ia participar do orçamento da família (.) você já ia conseguir melhorar um pouquinho as condições mesmo de vida (.) então hoje o que eu vejo embora eu defenda toda 
a proposta que hoje tem sido discutida sobre educação sobre ensino médio embora eu a defenda (.) eu entendo que ela ainda não conseguiu se concretizar numa forma (.) eh (2) de maneira a tornar (3) tornar a escola interessante e com sentido prático pros meninos né porque a gente fala assim há prepara para o vestibular e para o PAS (.) mas a gente tem percebido que a minoria que busca o (3) PAS e o vestibular. né (1) e com essa abertura do ensino superior com esse número infinito de programas e de bolsas não necessariamente a escola eh (3) tem que agir como pré-vestibular, ela já perdeu até isso né (1) pra mim (.) o ensino médio está perdendo uma essência e que é uma consequência da perda de essência da própria escola né como eu tinha dito antes, mesmo quem não gostava de estudar na minha época ia à escola porque ela é quem poderia oferecer uma subidinha uma ascensãozinha (.)

Cf: À medida que o tempo foi passando (.) aí fazendo aquela pergunta né (.) como é que eles (2) na época que a gente estudava, se havia essa preocupação com o ensino médio e eu sempre reitero aquilo que eu estava falando ontem com o Eduardo a gente era muito pobre Então (.) ensino médio era status era status e assim, porque os nossos pais tinham mal a quarta série (.) meus pais só tiveram até a quarta série né (2) sabiam ler e escrever então, a gente tinha essa perspectiva (.) parecia assim era a algo inatingível inclusive né (2) até você tinha de fazer prova de seleção para entrar no ensino médio (.) eu acho que os alunos levavam muito a sério até porque o índice de reprovação era muito pequeno nossa, de uma turma de uns 35 (.) porque as turmas não eram grandes né (.)

Bm: E tinha uma cobrança maior (.)

Cf: Isso, havia uma cobrança maior e numa turma de 35 (.) 02 reprovavam e há um detalhe (.) a gente via a reprovação como um fracasso, diferente de hoje né então (.) essa relação que eu vejo hoje com os meninos com o ensino médio e é um número muito grande é que pra eles é só uma fase que vai passar e que não vai influenciar muito na vida deles né mas pra gente tinha muita importância (.)

Bm: É muito importante, mesmo porque o ensino médio acontece em uma fase da vida né (1) do ser humano (.) onde é uma fase de transição de tomar decisões, o que vai cursar o que pensa em ser no futuro e tal é muito importante. infelizmente (.) nem todos os jovens tem maturidade, porque os jovens de hoje por incrível que pareça são bem menos imaturos, bem mais imaturos do que antigamente né (2) com todo o conhecimento que tem aí mas se tornam mais imaturos são pessoas que chegam aí há 18 anos sem saber direito o que querem da vida (.)

Seguindo a dinâmica proposta para os grupos, ou seja, não interromper os participantes enquanto estão discutindo (Bohnsack, 2014b), a pergunta a respeito do ensino médio na atualidade fez com que eles se voltassem ainda mais às suas próprias experiências como estudantes do antigo $2^{\circ}$ grau. Enquanto sujeitos que alcançaram novas posições sociais com a conquista do diploma de $2^{\circ}$ grau em um período no qual poucos chegavam a essa etapa, os professores questionam a falta de um "sentido útil" e "prático" para a escola de nível médio na atualidade, aspecto reforçado, sobretudo, pelo docente Am, mas ratificado pelas colegas Cf e Bf. Na perspectiva dos participantes, esse sentido estaria associado à possibilidade de garantir uma "ascensãozinha" que hoje não está mais dada pela escola de nível médio. O diploma de $2^{\circ}$ grau, por ser de acesso para poucos, gozava de status. Atualmente, o status foi transferido para o diploma adquirido na educação 
superior e, por esse motivo, a escola parece ter perdido seu sentido prático. Nas palavras de Am, o ensino médio está "perdendo uma essência" que tem como consequência uma "perda de essência da própria escola". Para os participantes do grupo Outrora, a preparação para exames que dão acesso à educação superior, como o vestibular e o Programa de Avaliação Seriada (PAS), que possibilita o ingresso na Universidade de Brasília - UnB (Ribeiro, 2017), não deve constituir um fim prático e tampouco - nisso estamos plenamente de acordo - pode ser tomada como a essência da escola. Esta, ao preocupar-se com o ingresso na universidade, coloca em segundo plano a preparação para outros cursos de vida após a conclusão do ensino médio capazes de promover ascensão social, perdendo, dessa forma, a sua "essência", que na visão do grupo Outrora consiste em proporcionar uma melhoria da condição material dos estudantes e de suas famílias.

Com relação ao ensino médio atual, não há propriamente uma avaliação deste. Bm acrescenta que os jovens estão passando por uma fase de "transição" e de reflexões sobre a vida e o futuro, mas que são "bem imaturos" ou "mais imaturos" do que os estudantes no passado, pois chegam aos 18 anos "sem saber direito o que querem da vida". Trabalhar no sentido de auxiliá-los na construção de "projetos de vida" (cf. Leão; Dayrell; Reis, 2011; Weller, 2014) e na superação da "imaturidade", não é apontado como um trabalho essencial a ser realizado pela escola, ainda que os participantes defendam "toda a proposta que hoje tem sido discutida sobre educação".

\section{Grupo Presente: foco nos exames e no "olhar para o mundo"}

O grupo de discussão teve início com a mesma pergunta realizada para o Outrora, ou seja, voltada para a narrativa das experiências dos participantes como estudantes no ensino médio na primeira década dos anos 2000 (passagem inicial: ensino médio no passado).

Y: Eu gostaria que vocês falassem como foi a experiência de vocês durante o ensino médio, o que vocês acham, onde vocês fizeram o ensino médio, como foi a experiência de vocês no ensino médio enquanto alunos, como foi a formação de vocês

Fm: Bem, eu estudei no YY lá no Plano, cara (2) eu não era um aluno muito dedicado mas eu tinha as matérias as quais eu tinha mais facilidade, então assim eh (3) em grande parte o ensino médio me permitiu me aprofundar em algumas coisas. descobrir alguns interesses (.) que depois eu acabei desenvolvendo uma boa orientação em relação ao que eles vieram ((trecho inaudível)) separação bem, grande eu tive bastante dificuldade com as exatas e foi bem natural (3) da liberdade que eu tive de poder comparar (3) eu transitar na ((trecho inaudível)) professores (.) ter que correr atrás de provas e isso me dava (.) me causava alguma dificuldade porque eu tinha de correr atrás mas (.) também tem de recordação mais tocante do ensino médio acho que foi essa assim (.) de responsabilidade, ter que correr atrás de algumas coisas porque eu sabia a própria coordenação da escola não ia fazer isso por mim (.) eu devo ter feito entre 2002 (.) 2004 (.)

Gf: Eu fiz o ensino médio no Rio de Janeiro só que era na Baixada, um pouco diferente daqui de Brasília ((trecho inaudível)) Informática, não era sala ambiente e a visão era técnica, mesmo por isso que eu 
fui fazer faculdade. terminava o ensino médio ia pro trabalho, mesmo terminando o ensino médio você teria que entrar no mercado de trabalho, culturalmente fez 18 anos você é independente, (2) minha escola era muito rígida, então (.) a gente tinha alguns sistemas como se fosse um colégio militar, mesmo (.)

Hf: A formação especificamente falando (.) na época eu não tinha essa noção, eu não tinha noção eh (3) do peso que aqueles anos (.) aquelas intervenções eh (3) pelas quais eu passava em sala de aula e fora da sala de aula (.) eu não tinha noção do peso que elas representariam pra mim eh (1) em todos os âmbitos da minha vida (.) eu não tinha noção do quão esse momento era (.) essa formação era (1) então de certa forma eu assim (.) como a maioria (.) eu levava como uma fase necessária, mas não tinha noção do quão importante essa fase era embora eu sempre tenha sido uma boa aluna eu não (.) eu não me via como agente transformador de nada não (.) eu me via como uma adolescente que tinha que cumprir aquela etapa pra poder passar pra próxima etapa e não como um momento que contribuiria pra minha formação (.) não só no que se refere à minha vida pessoal mas (.) à vida da minha comunidade. da minha sociedade (.) da sociedade da qual eu faço parte (.) da minha família (.) enfim do meu país (1) eu não tinha essa dimensão assim, da importância que eu enquanto aluno de uma escola de segundo grau do Gama tinha em relação ao mundo (.) ao mundo do outro e ao mundo coletivo (.)

Entre os participantes do grupo Presente, uma professora cursou o ensino médio no Rio de Janeiro concomitantemente ao trabalho (Gf) e dois estudaram em escolas públicas do Distrito Federal em tempo integral, uma delas localizada na região central de Brasília (Fm) e outra no Gama (Hf). Essa geração de professores representada pelo grupo Presente se distingue da mais velha, representada pelo grupo Outrora, por haver ingressado no magistério somente após a conclusão do curso superior. Também se diferencia por seus componentes terem estudado em universidades públicas, enquanto os do grupo Outrora frequentaram cursos superiores em instituições privadas e concomitantemente ao trabalho.

Ao serem convidados a narrar suas experiências enquanto estudantes do ensino médio, os professores do grupo Presente realizam uma espécie de teorização sobre como haviam se comportado como estudantes (com exceção de Gf, que destaca as dificuldades de conciliação de estudos e trabalho/estágio). Apesar de não ser "muito dedicado", Fm aponta que o ensino médio possibilitou a descoberta de interesses decisivos para a escolha do curso superior e que o fato de "ter que correr atrás de algumas coisas" por conta própria, embora causasse "alguma dificuldade", também foi determinante para que assumisse sua trajetória escolar com "responsabilidade". A professora Hf, apesar de sempre ter sido "uma boa aluna", não compreendia a importância do ensino médio como uma etapa que contribuiria para a sua formação como um todo e o lugar social que ocupava enquanto estudante dessa etapa no Gama.

Conhecer os significados que os participantes conferem ao ensino médio na atualidade permitiu compreender também a visão de professores que, há pouco tempo, ocupavam a posição de estudantes (passagem inicial: ensino médio no presente). 
Y: O ensino médio de hoje é diferente do ensino médio que vocês estudaram

Fm: Eu não sei quanto as outras escolas, eu acho que em geral e no CEM XX é assim (.) tem uma visão de preparar o jovem de vestibular, de Enem, de PAS, apesar de que tinham bastante liberdade (.) a minha aula (.) ligadas a vestibular e tal (.) no meu caso específico não é o meu mote assim (1) os alunos têm essa possibilidade de trazer a gente trabalhar em cima de questões que é pra eles se prepararem pra prova, mas eu particularmente acho que tipo (1) para como o olhar para o mundo assim (.) utilizar em qualquer âmbito independente do que eles forem fazer né (.) mas sempre tem esse $Q$, que a gente vive nas escolas sempre, tem nas provas (.) mas particularmente nas minhas aulas eu tento que isso não seja o único viés (.) trabalhar vislumbrando o trabalho, o vestibular [...] na última década a possibilidade de você entrar na universidade (.) com essas possibilidades aumentaram formas avaliativas diferentes acabou que aumentou a importância do ensino médio né e também esse foco nas provas né e por mais que às vezes esse foco de provas seja um pouco limitador porque você tem que ater a questões de certo e errado (.) por outro lado você tem o PAS, por exemplo (.) que é um tipo de avaliação que exige um posicionamento mais crítico, uma análise mais aprofundada do aluno e isso na minha aula contribui bastante né porque a preocupação deles em escrever uma redação ficar ligado no contexto político do país e eles possam escrever sobre isso (.) faz com que minha aula tenha mais (.) eh (2) de tratar a história a partir dos problemas da atualidade (.) eles estão vendo na TV então (.) eu acho que o contexto político interfere positivamente (.)

Gf: L com o pensamento de entrar na faculdade mesmo PAS, eh (2) Enem, né essa contribuição também do contexto político da possibilidade e dele (2) que ele pode estudar porque ele tem a vaga dele lá né não é tão impossível como era antes (.) porque antes se pensava né não vou conseguir? hoje não, hoje se eu quiser, eu consigo? então isso contribuiu bastante (.) o contexto político contribuiu bastante para estimular a estudar mais porque via-se a possibilidade de entrar na faculdade (.) na minha área não vejo o ensino médio mudar muito de dez anos pra cá por que a gente não trata muito da questão política né mais a parte prática, talvez tenha mudado (.) por quê porque eu posso realmente dar aquele conteúdo que vai puxar um pouquinho mais né (.) porque vai cair lá no vestibular, se for pensando somente visando essa parte porque a gente pega a parte teórica que é o conhecimento do dia a dia que ele tem que ter (.) tem que saber quando ele liga uma lâmpada o que que acontece ali e tal (.) mas a gente sabe muitas vezes ele fala (.) há, isso aí eu não vou usar pra nada, mas (.) vai usar pra quê pelo menos para o vestibular ele tem que estudar (.)

Hf: Eu acredito que os jovens de antes eles entendiam menos o seu papel (.) sua função, e talvez por isso se dedicassem mais às questões relacionadas a conteúdo, à matéria, à sala de aula naquela forma, naquele formato mais tradicional possível (.) conteúdo (.) matéria (.) caderno (.) prova (.) aprovação (.) certificado (.) os jovens da minha época viam o ensino médio e a formação acadêmica de uma maneira muito mais distanciada das relações sociais inclusive quando eu penso no que estava acontecendo politicamente em torno de mim no momento em que eu era aluna eu não sei (.) não lembro não (2) assim é como se eu não tivesse vivido esse momento e foi bem isso que aconteceu (.) não vivi o momento político do país não (.) isso não fazia parte da minha formação enquanto aluna e da minha formação enquanto cidadã, eram coisas estanques eh (2) embora a minha família sempre teve algum engajamento político, mas isso não era associado à escola, isso era uma coisa específica da minha, família então nem eu tinha noção 


\begin{abstract}
de que aquilo era parte de um todo muito maior que eu desconhecia eu acreditava que era um posicionamento relacionado às pessoas da minha família e não à necessidade que se tem pra ser um cidadão e fazer parte desse contexto político social eh (2) então eu acredito que os alunos da minha época se posicionavam de uma maneira diferente diante das coisas (.) os alunos de hoje talvez tratem com mais irresponsabilidade questões relacionadas à formação (.) ao estudo em si ao conhecimento mas eles estão muito mais voltados pro engajamento social e político (.) na minha opinião eles estão muito mais interessados em fazer parte disso em debater, essas questões em aprender sobre isso o que eu acho que é muito mais importante eu acho que deve ser realmente priorizado diante de qualquer aprendizado técnico teórico que o aluno vai esquecer no próximo ano (.) então eu vejo sim uma melhora, eh (2) uma enquanto professora hoje eu vejo que os jovens de hoje são muito mais engajados que os jovens da minha época $e$ isso é muito bom!
\end{abstract}

Os professores Fm e Gf destacam que o ensino médio na escola em que atuam está basicamente voltado para a preparação para os exames que dão acesso à educação superior, especialmente o Exame Nacional do Ensino Médio (Enem) e o Programa de Avaliação Seriada (PAS) da Universidade de Brasília, tendo em vista o aumento da "possibilidade de você entrar na universidade", sobretudo na "última década", que, embora não mencionado diretamente pelos participantes, decorre da implementação de cotas nas universidades federais e estaduais para estudantes oriundos de escolas públicas e de financiamentos por meio de programas como o Fundo de Financiamento Estudantil (Fies) e o Programa Universidade para Todos (Prouni). Apesar do aspecto "limitador" das provas, Fm procura incentivar análises aprofundadas da história mediante "problemas da atualidade" que colaborem para um "posicionamento mais crítico" e um "olhar para o mundo", que, além de serem cobrados nas redações dos exames, contribuirão na formação desses jovens como um todo. Mais adiante, no decorrer do grupo de discussão, esse posicionamento é exemplificado pelo professor da seguinte maneira: "Eu acho que é importante que o jovem comece a ter uma vivência política já no ensino médio pra que ele possa amadurecer e possa ser um cidadão atuante, que não fique apenas preso à questão do voto, que ele possa sim acompanhar, que ele possa sim ser crítico aos processos sociais".

Gf ratifica a proposição de Fm de que ingressar na educação superior não é mais "tão impossível como era antes", o que faz com que o jovem também se interesse pelo "conteúdo que vai puxar um pouquinho mais né, porque vai cair lá no vestibular", referindo-se, nesse caso, aos conteúdos de Física. A apropriação teórica de conteúdos não culmina, no entanto, em um entendimento prático acerca da importância da Física no cotidiano, por exemplo, sobre o que acontece quando se "liga uma lâmpada". Já Hf, ao afirmar que os estudantes atualmente tratam "com mais irresponsabilidade questões relacionadas à formação, ao estudo em si, ao conhecimento, mas eles estão muito mais voltados pro engajamento social e político", faz isso comparando com sua experiência enquanto estudante do ensino médio, em que declara não ter vivido "o momento político do País" dentro da 
escola e se dedicado mais aos conteúdos das disciplinas "naquele formato mais tradicional possível". Apesar do engajamento político de sua família, não havia uma conexão entre o posicionamento familiar no tocante a determinados temas e a relação destes com a escola, como "parte de um todo muito maior", ou seja, que diz respeito tanto à instituição família quanto à instituição escola.

Chama atenção, entre os professores do grupo Presente, a importância atribuída à formação integral dos jovens no ensino médio, de forma que possam reconhecer a função social que ocupam na sociedade e desenvolver uma consciência crítica para além da preparação para os exames de acesso à educação superior. Por outro lado, esses professores tampouco manifestam preocupação no que se refere aos projetos de vida dos estudantes ou os percebem apenas em relação ao propósito de ingressar em um curso superior. Apesar de não mencionado diretamente pelos professores, o pano de fundo dessas reflexões remete, possivelmente, ao contexto político pelo qual o Brasil estava passando em 2016, marcado, entre outros, pelo impeachment da Presidenta Dilma Roussef e por intensas mobilizações estudantis em todo o País, especialmente em escolas de ensino médio que passaram a ser ocupadas. Nesse cenário, os professores parecem entender o interesse dos estudantes de "fazer parte disso", ou seja, de fazer parte de um movimento que questionou os acontecimentos políticos e seus desdobramentos.

\section{Análise comparativa dos grupos}

No que concerne ao grupo Outrora, as comparações com o $2^{\circ}$ grau profissionalizante instituído durante a ditadura militar foram recorrentes. Os professores partilham da concepção de que o ensino médio perdeu sua identidade e que ainda não adquiriu um novo significado, mesmo admitindo que ocorreram mudanças pedagógicas positivas após o término da ditadura. O grupo reconheceu a importância do ensino médio atual e que essa etapa da educação básica é crucial para a continuidade dos estudos, mas manifestou preocupação em relação à contribuição do ensino médio para o acesso imediato dos jovens ao mercado de trabalho, pois, mesmo com a melhoria social dos moradores da região administrativa do Gama e de regiões próximas, muitos jovens precisam trabalhar e nem todos podem ou desejam ingressar em uma instituição de educação superior.

Os participantes do grupo Presente apontaram avanços no que se refere às questões pedagógicas da escola de ensino médio e em relação aos estudantes que gozam de mais oportunidades de acesso à educação superior do que as gerações passadas. O grupo refletiu sobre as responsabilidades dos professores quanto a trabalharem de forma a atender não só os jovens que pretendem ingressar em um curso superior, entendendo que se deve priorizar a formação integral, sem esquecer que o ensino médio precisa contribuir para a preparação do cidadão ético e crítico, independentemente 
da função que ele vá desempenhar na sociedade, seja de nível superior, técnico ou médio. Nessa perspectiva, o ensino médio não representa apenas uma fase de transição: ele integra um momento importante que favorece a preparação dos sujeitos enquanto cidadãos.

Os debates sobre os sentidos e significados do ensino médio a partir da LDB, Lei $n^{\circ}$ 9.394/1996, também geraram divergências entre os grupos. O caráter de dualidade que caracterizou o ensino médio, em quase toda a sua história, também se mostrou importante nos discursos dos docentes antigos e perdeu relevância nas interações dos professores mais jovens. Em outras palavras, os docentes do grupo Presente não precisaram pensar na profissão que seguiriam logo após o término do ensino médio, como aconteceu com os do grupo Outrora. Puderam realizar essa escolha ao adentrarem no curso superior.

Entre os aspectos centrais que orientam os discursos dos dois grupos e que também os distinguem, podemos destacar: a análise contemporânea à luz da memória do passado; a função social da escola (para os dois grupos, o espaço escolar é um espaço de interação); o ensino médio como garantia de futuro; e a interação do corpo docente com os jovens estudantes. Os sentidos atribuídos ao ensino médio são distintos, ainda que os dois grupos geracionais estejam convivendo no mesmo espaço e tempo da escola. Percebe-se que a memória acessada enquanto estudantes se constituiu como base de orientação para os dois grupos no período atual e que esses significados também influenciam as orientações coletivas em referência aos jovens que frequentam atualmente o ensino médio.

Ainda que o contexto histórico, social e político possa mudar as relações e os conteúdos delas, certo é que a escola permanece como base para essas relações. Percebe-se - tanto no grupo Outrora como no Presente - uma mudança na concepção pedagógica que passou a colocar o estudante no centro do processo, fazendo com que seus posicionamentos fossem valorizados. Essas mudanças também alteraram as relações entre professores e estudantes, permitindo uma participação mais ativa dos jovens do ensino médio nas temáticas propostas em sala de aula (Candau, 2002).

\section{Considerações finais}

A trajetória deste estudo foi orientada pelos princípios da pesquisa qualitativa reconstrutiva, em que as orientações coletivas de professores mais velhos e mais jovens sobre o ensino médio foram analisadas com base no Método Documentário. O método propiciou a análise das interações dos sujeitos e das visões destes a respeito de temáticas abordadas nos grupos de discussão, procurando compreender como se constituíram tais orientações e não somente o que elas revelam. Embora não tenha esgotado as reflexões e discussões sobre o tema, a reconstrução das orientações coletivas de docentes de distintas gerações, perpassando suas trajetórias enquanto estudantes e professores, possibilitou refletir sobre essa etapa da educação mediante uma perspectiva pouco explorada quando se busca uma compreensão do ensino médio. 
O momento histórico que vivemos é fruto de todo um contexto de ordem social, econômica e cultural construído no tempo. Conhecer como se deu essa construção e sua relação com o presente permitiu estabelecer algumas considerações sobre o ensino médio, entre outras, a função da escola e a relação entre estudantes e professores. Se em épocas passadas a relação era de obediência e hierarquia, por conta das questões culturais e do momento ditatorial que se vivia no País, no tempo presente, a relação entre professores e estudantes ganha outros contornos. Atualmente, a valorização do corpo discente e o papel desempenhado pelo corpo docente conferem ao convívio um caráter recíproco, com hierarquias que - nos termos de Hannah Arendt (2005) - pautam-se mais pela autoria e não pelo exercício autoritário do mestre. Os posicionamentos dos alunos são incorporados nas aulas e em outras atividades, possibilitando discussões em torno de temáticas tanto políticas quanto econômicas e sociais.

Por último, enfatizamos a necessidade de a escola transcender seu papel formal de instituição educadora e abrir-se para as orientações dos atores que integram o ambiente escolar. São estudantes, professores, gestores, auxiliares da educação, pais e responsáveis que movem a máquina educacional de forma tão única e revelam que sua essência também pode estar na essência da própria vida, no que concerne à necessidade da interação, do diálogo, das ações, dos objetivos e do olhar crítico, considerando sempre que a centralidade deve recair sobre os principais sujeitos que frequentam a escola, os estudantes.

\section{Referências}

ARENDT, H. Entre o passado e o futuro. São Paulo: Perspectiva, 2005.

BOHNSACK, R. Documentary method. In: FLICK, U. (Ed.). The SAGE handbook of qualitative data analysis. London: Sage, 2014a. p. 217-233.

BOHNSACK, R. Rekonstruktive sozialforschung: einführung in methodologie und praxis qualitativer forschung. 9. ed. Opladen \& Toronto: Barbara Budrich, 2014b.

BOHNSACK, R.; WELLER, W. O método documentário na análise de grupos de discussão. In: WELLER, W.; PFAFF, N. (Org.). Metodologias da pesquisa qualitativa em educação: teoria e prática. 3. ed. Petrópolis: Vozes, 2013. p. 67-86.

BOSI, Ê. Memória e sociedade: lembranças de velhos. 3. ed. São Paulo: Companhia das Letras, 1994.

BRASIL. Emenda constitucional n 59 , de 11 de novembro de 2009. Acrescenta $\S 3^{\circ}$ ao art. 76 do Ato das Disposições Constitucionais Transitórias para reduzir, anualmente, a partir do exercício de 2009, o percentual da Desvinculação das Receitas da União incidente sobre os recursos destinados à manutenção e desenvolvimento do ensino de que 
trata o art. 212 da Constituição Federal, dá nova redação aos incisos I e VII do art. 208, de forma a prever a obrigatoriedade do ensino de quatro a dezessete anos e ampliar a abrangência dos programas suplementares para todas as etapas da educação básica, e dá nova redação ao § $4^{\circ}$ do art. 211 e ao $\S 3^{\circ}$ do art. 212 e ao caput do art. 214, com a inserção neste dispositivo de inciso VI. Diário Oficial da União, Brasília, DF, 12 nov. 2009. Seção 1, p. 8.

BRASIL. Lei no 5.692, de 11 de agosto de 1971. Fixa Diretrizes e Bases para o ensino de $1^{\circ}$ e $2^{\circ}$ graus, e dá outras providências. Diário Oficial da União, Brasília, DF, 12 ago. 1971. Seção 1, p. 27883.

BRASIL. Lei no 9.394, de 20 de dezembro de 1996. Estabelece as diretrizes e bases da educação nacional. Diário Oficial da União, Brasília, DF, 23 dez. 1996. Seção 1, p. 6377.

BRASIL. Lei $\mathrm{n}^{\circ} 13.415$, de 16 de fevereiro de 2017. Altera as Leis $\mathrm{n}^{\circ} \mathrm{s}$ 9.394, de 20 de dezembro de 1996, que estabelece as diretrizes e bases da educação nacional, e 11.494, de 20 de junho 2007, que regulamenta o Fundo de Manutenção e Desenvolvimento da Educação Básica e de Valorização dos Profissionais da Educação, a Consolidação das Leis do Trabalho - CLT, aprovada pelo Decreto-Lei $\mathrm{n}^{\circ} 5.452$, de $1^{\circ}$ de maio de 1943, e o Decreto-Lei $n^{\circ} 236$, de 28 de fevereiro de 1967; revoga a Lei $\mathrm{n}^{\circ}$ 11.161, de 5 de agosto de 2005; e institui a Política de Fomento à Implementação de Escolas de Ensino Médio em Tempo Integral. Diário Oficial da União, Brasília, DF, 17 jan. 2017. Seção 1, p. 1.

BRASIL. Instituto de Estudos e Pesquisas Educacionais Anísio Teixeira (Inep). Censo da Educação Básica 2019: resumo técnico. Brasília, DF: Inep, 2019.

CANDAU, V, M. Sociedade, cotidiano escolar e cultura (s): uma aproximação. Educação \& Sociedade: Revista de Ciência da Educação, Campinas, v. 23, n. 79, p. 127-159, ago. 2002.

DAMASCO, D. G. B. Contando uma história: o ensino público de línguas estrangeiras a partir das interpretações de jovens e de docentes do Distrito Federal. 2014. 463 f. Tese (Doutorado em Educação) - Faculdade de Educação, Universidade de Brasília, Brasília, DF, 2014.

FERREIRA, C. S. O ensino médio do Distrito Federal em números. In: WELLER, W.; FERREIRA, C. S.; BENTO, A. L. (Org.). Juventude e ensino médio público no Distrito Federal: percepção de professores, gestores e estudantes. 2. ed. Belo Horizonte: Fino Traço, 2019.

KRAWCZYK, N. Reflexão sobre alguns desafios do ensino médio no Brasil hoje. Revista Cadernos de Pesquisa, São Paulo, v. 41, n. 144, p. 752-769, set./dez. 2011.

LEÃO, G.; DAYRELL, J. T.; REIS, J. B. Juventude, projetos de vida e ensino médio. Educação \& Sociedade: Revista de Ciência da Educação, Campinas, v. 32, n. 117, p. 1067-1084, out./dez. 2011. 
MANNHEIM, K. El problema de las generaciones. Revista Española de Investigaciones Sociológicas (REIS), Madrid, n. 62, p. 193-242, 1993.

MANNHEIM, K. Structures of thinking. London: Routledge, 1982.

PEREIRA, E. W.; ROCHA, L. M. F. Anísio teixeira e o plano educacional de Brasília. In: PEREIRA, E. W. et al (Org.). Nas asas de Brasília: memórias de uma utopia educativa (1956-1964). Brasília, DF: Ed. UnB, 2011. p. 27-45.

RIBEIRO, D. H. M. O sucesso da rede pública no Programa de Avaliação Seriada (PAS): análise do desempenho dos alunos da rede pública no PAS da UnB no $1^{\circ}$ Semestre de 2016. Revista com Censo: Estudos Educacionais do Distrito Federal, Brasília, DF, v. 4, n. 4, p. 95-97, nov. 2017.

SIMÕES, G. A. M.; DARTORA, L.; DEUS, L. P. A. Análise dos modelos de reorganização do tempo-espaço escolar para o Ensino Médio e da Semestralidade no Distrito Federal. Revista com Censo: Estudos Educacionais do Distrito Federal, Brasília, DF, v. 4, n. 4, p. 157-165, nov. 2017.

TATAGIBA, A. B.; SILVA, D. E. G. Discursos da exclusão na geografía de Brasílía-DF. Cadernos de Linguagem e Sociedade, v. 14, n. esp. p. 128-146, 2013.

TEIXEIRA, A. Plano de Construções Escolares. Revista Brasileira de Estudos Pedagógicos, Rio de Janeiro, v. 35, n. 81, p. 195-199, jan./mar. 1961.

VASCONCELOS, R. D. A formação humana integral: o processo de construção de Brasília e a educação. In: PEREIRA, E.; COUTINHO, L. M.; RODRIGUES, M. A. M. Anísio Teixeira e seu legado à educação do Distrito Federal: história e memória. Brasília, DF: Ed.Universidade de Brasília, 2018. p. 303-320.

WELLER, W. Grupos de discussão na pesquisa com adolescentes e jovens: aportes teórico-metodológicos e análise de uma experiência com o método. Educação e Pesquisa, São Paulo, v. 32, n. 2, p. 241-260, maio/ ago. 2006.

WELLER, W. Jovens no ensino médio: projetos de vida e perspectivas de futuro. In: DAYRELL, J.; CARRANO, P.; MAIA, C. L. (Org.). Juventude e ensino médio: sujeitos e currículos em diálogo. Belo Horizonte: Editora UFMG, 2014. p. 135-151.

Recebido em 20 de abril de 2020.

Aprovado em 4 de novembro de 2020. 